\title{
O CONCEITO DE INFÂNCIA NA PERSPECTIVA DE MÃES USUÁRIAS E NÃO USUÁRIAS DE CRECHE ${ }^{1}$
}

\author{
Catarina de Souza Moro ${ }^{2}$ \\ Paula Inez Cunha Gomide \\ Universidade Federal do Paraná
}

\begin{abstract}
Resumo: O objetivo deste trabalho foi conhecer as concepções maternas sobre a infância a partir da interpretação das falas verificadas em entrevistas com 30 mães, das quais 15 utilizam o sistema público de educação infantil. A análise do conteúdo das entrevistas foi feita trabalhando-se com categorias provenientes das falas das participantes, reunidas em 4 conjuntos temáticos: (1) A criança hoje: características e necessidades, (2) Dificuldade na criação dos filhos na atualidade, (3) Erros mais comuns na educação dos filhos e (4) Participação masculina na educação e no cuidado dos filhos. Os dados encontrados indicam que houve similaridade nas concepções de mães usuárias e não usuárias do sistema público de creches, em relação aos assuntos que envolviam infância e práticas de cuidado e educação no contexto familiar. Discute-se a influência da utilização do ambiente coletivo público nas idéias parentais sobre educação na família.
\end{abstract}

Palavras-Chave: infância; concepções maternas; creches; política de educação infantil

\section{CHILDHOOD CONCEPT FOR MOTHERS WHO DO AND DO NOT USE DAY-CARE CENTERS}

\begin{abstract}
The intent of this paper was to understand the motherly conceptions about childhood through the interpretation of speeches obtained from interviews with 30 mothers, where 15 of them make use of the public education system for children. The analysis of the interviews were made through categories that appeared in the speeches, grouped in four different topics: (1) The children today: characteristics and needs, (2) Difficulties for nurturing nowadays, (3) Common mistakes in children's education and (4) Masculine participation in children's care and education. The data found pointed out similarities in the conceptions of mothers that use the infant day care public system and those that do not use it, mainly related to subjects that involve childhood and practices of care and education in the family context. It was discussed the influence of collective setting use on parents ideas about family education.
\end{abstract}

Key-Words: childhood; maternal conceptions; day care centers; childhood education policies

São inúmeras as mudanças sociais e familiares ocorridas da segunda metade do século XX, implicando em transformações significativas, no tocante à educação dos filhos.

\section{Família, Sociedade e Infância: muitas transfor- mações}

Caldana (1995) afirma que em cinqüenta anos houve uma transformação radical quanto ao ideário

\footnotetext{
${ }^{1}$ Artigo recebido para publicação em 22/05/03; aceito em 06/08/03.

${ }^{2}$ Endereço para correspondência: Catarina de Souza Moro, Rua Edgard Stelfeld, 525, Jardim Social, Curitiba, PR, Cep 82530-000, E-mail: catarina@duplob.com.br
}

e as orientações relacionadas à criação e educação dos filhos. Entre os anos 30 e 80, a educação da criança passou de um sentido "moral" (em que a preocupação central eram os "bons" comportamentos) para um sentido "psicológico" (em que o foco é a "saúde emocional"). Houve uma mudança de modelo: antes hierárquico, hoje igualitário; mas o que se espera da criança, ainda é que ela se adapte ao grupo e acate normas. É importante lembrar que esta alteração nos estilos parentais trouxe consigo uma série de decorrências, que privilegiaram a educação permissiva (ausência de regras, controle frouxo, falta de supervisão) que está correlacionada com o desen- 
volvimento de comportamentos anti-sociais (Gomide, no prelo).

O contexto urbano incita novas formas de relacionamento social: de um lado ocorre uma elevação das relações intrafamiliares, de outro diminuem as relações comunitárias e de vizinhança, favorecendo o isolamento e o anonimato; o interesse dos pais volta-se unicamente para os filhos, incorrendo em atenção e proteção excessivas; a criança carece de múltiplos modelos de adulto para se referenciar e, além disso, o contexto metropolitano não oferece muitas oportunidades para o convívio social infantil entre pares, a não ser em espaços institucionais (Anolli \& Mantovani, 1998; Rosemberg, 1998).

Vive-se também nos dias atuais a emergência de uma nova figura de pai. Os trabalhos de Grisci (1994) e Trindade (1998) indicam que é muitíssimo recente na pesquisa científica a preocupação com a figura masculina nas relações familiares. Para Grisci a ideologia da maternidade como dom natural, sagrado, além de ser fictício, dilui a responsabilidade social de todos os seres humanos no processo de criação e educação das crianças. Trindade explicita que os papéis masculino e feminino se acham cristalizados dicotomicamente, e que, apesar da diversidade de modelos familiares na sociedade atual, persiste a concepção tradicional e estereotipada das atividades do homem e da mulher no contexto sócio-familiar e o estabelecimento de relações desiguais.

$\mathrm{Na}$ realidade brasileira tem se tornado cada vez mais comum famílias chefiadas por mulheres. De acordo com os dados do IBGE (Brasil, 2000) desde a década de 80 vem crescendo de maneira regular a proporção de domicílios chefiados por mulheres, que era $16,9 \%$ e $18,2 \%$ em 1981 e 1985, aumentando respectivamente para $20,3 \%$ e $22,9 \%$ nos anos de 1990 e 1995, e em 1999 atingiu 26\%.

A contemporaneidade apresenta peculiaridades em termos sócio-culturais que podem ser responsáveis pelas modificações, não apenas sociais e familiares, mas da própria subjetividade humana.

\section{Espaço Social para a Infância: a educação infantil}

Sabe-se que a infância não é uma categoria natural, mas histórica e cultural; os conhecimentos produzidos acerca desta temática têm estreita liga- ção com o lugar social que a criança ocupa na relação com o outro (Áries, 1981; Gagnebin, 1997; Pereira \& Souza, 1998). Esse espaço social tem mudado muito nas últimas décadas. Nos anos 50 as crianças participavam ativamente da vida comunitária, pois tinham o direito de freqüentar a rua, lugar de livre circulação na época (Kuhlmann Júnior, 1998). Na atualidade, a infância se tornou um produto de consumo, em torno dela se estruturam padrões de conduta, de entretenimento, de criação e de educação e, mesmo de consumo (Muniz, 1999; Pereira \& Souza, 1998; Silveira, 1997). Faria (1999) comenta sobre a "dupla alienação da infância, à qual estariam sujeitas tanto as crianças ricas quanto as pobres, na antecipação de suas vidas de adultas, e indica a creche como lugar para se tornar criança, onde se descobre (e se conhece) o mundo através do brincar, das relações mais variadas com o ambiente, com os objetos e as pessoas, principalmente entre elas: as crianças” (p.72).

Neste locus privilegiado têm sido realizados trabalhos que possibilitam a revisão de algumas teorias e concepções sobre a infância quanto às relações de apego, à construção de conhecimentos, à capacidade de autonomia da criança pequena e ao seu desenvolvimento social, nas modalidades de interação adulto/criança e criança/criança, verificando-se sua capacidade de estabelecer múltiplas relações com seus pares, com as de outras idades e com os adultos, criando e inventando novas brincadeiras e novos significados. (Bufalo, 1997; Carvalho \& Beraldo, 1989; Ferreira, 1988; Oliveira, 1988; Pedrosa \& Carvalho, 1995; Rossetti-Ferreira \& Oliveira, 1993; Souza, 1994; Ugazio, 1992). A maioria destes estudos científicos tem se ocupado em pesquisar a criança e não o contexto da instituição de educação infantil em si ou como este interfere nas experiências e concepções dela ou de seus familiares (Moro, 2002).

Neste trabalho, ao se fazer referência à infância, fala-se do coletivo de crianças, considerando-se fundamental o entendimento de que não existe uma criança genérica, atemporal, descontextualizada. Da mesma forma, como não existe a criança fragmentada, isto é, uma durante o horário de permanência na creche e outra em casa. Para Bondioli e Mantovani (1998) “família e creche são consideradas como 'con- 
textos' que a criança experimenta e que devem ser integrados para que se evitem perigosas descontinuidades na experiência infantil.”(p. 35).

As instituições de educação infantil se tornaram uma necessidade e uma realidade nos dias atuais e, em função disto, têm sido debatidas nas dimensões política, pedagógica e econômica. Exemplo no Brasil são as publicações recorrentes do MEC (Ministério da Educação e do Desporto), através da COEDI (Coordenadoria Geral de Educação Infantil), desde 1993 e também de pesquisadores (Geis, 1994; Maistro, 1997; Merisse, 1996; RossettiFerreira e cols., 1998).

Para Rosemberg (1998), no caso dos Estados Unidos, esta necessidade se deve a três modificações sociais: a participação crescente da mulher no mercado de trabalho; o grande número de famílias monoparentais, chefiadas principalmente por mulheres; e o aumento da pobreza. A estas se seguem a existência de competitividade e a exigência, cada vez maior, de dedicação ao trabalho; o padrão demográfico (famílias com um filho ou com mais filhos havendo intervalos grandes entre um nascimento e outro) e o panorama urbano, impróprio para o convívio social entre crianças pequenas.

\section{Método}

O presente estudo caracterizou-se como descritivo, compreensivo ou interpretativo, sendo uma das formas de pesquisa qualitativa (Minayo, 1992).

O grupo de usuárias (15), mães com filhos menores de 6 anos atendidos no sistema público de Educação Infantil, foi contatado nos próprios Centros de EI, precisando obedecer a dois critérios: diversificação geográfica no município e possibilidade de formação dos sub-grupos para a entrevista (disponibilidade por parte das mães), ou seja, de acesso para coleta de dados. Das vinte e duas creches do município, fez-se entrevista em cinco delas, compondo cinco sub-grupos, de três mães cada um. As entrevistas foram realizadas nas dependências das creches/centros de EI, em salas cedidas para uso exclusivo da pesquisadora e do grupo de mães, durante a coleta dos dados. As mães que não tinham seus filhos, de até 6 anos, freqüentando estes centros municipais, compuseram o grupo de não usuárias (15).
Estas foram contatadas nos cinco Centros Sociais existentes no município, durante o período em que participavam de cursos ou de atividades físicas e esportivas, marcava-se um outro dia e horário para a entrevista em grupo. Em cada centro formou-se um subgrupo de mães não usuárias com três participantes cada; durante a entrevista utilizou-se uma sala, nas dependências dos centros sociais.

Os dados utilizados foram as falas, os relatos verbais das mães entrevistadas em sub-grupos (3 participantes em cada). Como estratégia para coleta de dados utilizou-se a Discussão de Grupo, sendo que cada entrevista sempre se constituiu em uma situação única, tendo seu "impacto social próprio" (Minayo, 1992). As entrevistas foram conduzidas com base em um roteiro aberto, elaborado especialmente para este fim, abordando questões sobre a infância, suas características e necessidades; responsabilidades e dificuldades na criação de filhos, nos dias de hoje; erros mais comuns cometidos pelos familiares. Os dados obtidos foram registrados em áudio e dez entrevistas foram transcritas na íntegra (uma de cada sub-grupo, sendo cinco sub-grupos de participantes usuárias de creches e mais cinco subgrupos de participantes não usuárias) para posterior categorização e análise.

\section{Perfil das participantes da pesquisa}

As 30 participantes, ao término da entrevista, informavam seus dados para caracterização da amostra (sem necessidade de identificação pessoal). As mães entrevistadas tinham entre 21 e 40 anos; a maioria $(73,33 \%)$ se encontrava casada (de fato ou legalmente); 33,33\% residiam em casas com até três pessoas e tinham quatro anos de escolarização; a média de filhos era de 2,16; a renda familiar mensal de $50 \%$ das participantes ficava entre dois e cinco salários mínimos, 36,66\% delas recebiam até dois salários mínimos e 13,33\% estava acima de cinco salários mínimos (a totalidade de mães deste percentual não utilizava a creche); a maioria das mães usuárias de creche $(66,67 \%)$ trabalhava como empregada doméstica, diarista ou mensalista. No grupo de mães não usuárias de creche, 46,67\% eram donas-de-casa e $26,67 \%$ estavam desempregadas naquele momento; as participantes que não utilizavam 
a creche tinham uma rede de apoio maior para auxiliálas no cuidado e na educação dos filhos em comparação com aquelas cujos filhos freqüentavam as creches (Moro, 2002).

\section{Análise do conteúdo das entrevistas}

Para análise das entrevistas buscou-se a definição de um método com contornos e procedimentos próprios, tendo servido como base os trabalhos de Lefèvre, Lefèvre e Teixeira (2000). A partir do roteiro de entrevistas, fez-se o agrupamento dos assuntos afins em 4 conjuntos temáticos, estabelecidos no intuito de organizar a compreensão dos dados, sendo: (1) A criança hoje: características e necessidades, (2) Dificuldade na criação dos filhos na atualidade, (3) Erros mais comuns na educação dos filhos e (4) Participação masculina na educação e no cuidado dos filhos.

Foram identificadas nas respostas das partici- pantes as frases-chave para cada conjunto temático. Em seguida procedeu-se à identificação de categorias. Depois, fez-se o cotejamento de categorias semelhantes e complementares entre as participantes do mesmo grupo, de usuárias ou de não usuárias. E, por último, reuniram-se as frases-chave, de acordo com as categorias, em discursos-síntese, que representavam as concepções peculiares de cada grupo e não de cada participante em separado. Por último, fez-se uma análise comparativa entre os dois grupos: de mães usuárias e não usuárias do sistema municipal de creches. Utilizou-se o mesmo procedimento para análise de todos os conjuntos temáticos, permitindo-se a preservação das falas originais das participantes na estruturação dos discursos-síntese.

\section{Resultados}

Nos quatro quadros, a seguir, podem-se observar as categorias encontradas para cada conjunto temático e grupo de participantes em separado.

Quadro 1: Categorias referentes a: “A criança de hoje: características e necessidades”.

\begin{tabular}{|c|c|}
\hline Mães usuárias de creche & Mães não usuárias de creche \\
\hline $\begin{array}{l}\text { Não liga, não tão nem ấ } \\
\text { E muito inteligente } \\
\text { Dar limite é importante } \\
\text { Ensinar as responsabilidades para a criança } \\
\text { Ir conversando, explicando } \\
\text { Cuidar, dar carinho, atenção } \\
\text { Quer fazer o que ela quer } \\
\text { Sente necessidade de contar comigo }\end{array}$ & $\begin{array}{l}\text { Não obedece } \\
\text { Já nasce sabendo tudo } \\
\text { Depende muito da gente } \\
\text { Pedindo que queria ir para a escola } \\
\text { Tem que dobrar a atenf̧äo } \\
\text { Precisa de limite } \\
\text { Deixar mais à vontade } \\
\text { Comecei a ensinar desde pequeno } \\
\text { Precisa do modelo, do exemplo } \\
\text { Devia estar encaminhada para uma creche }\end{array}$ \\
\hline
\end{tabular}

As categorias apresentadas no Quadro 1 referem-se ao conjunto temático "A criança de hoje: características e necessidades”. As categorias Não liga, não tão nem aí, São muito inteligente, Quer fazer o que ela quer - das mães que utilizam as creches e - Não obedece, Já nasce sabendo tudo, Pedindo que queria ir para a escola - das mães que cuidam e educam os filhos em casa, denotam uma concepção de criança como ser sócio-histórico, o que implica entender o papel que a criança desempenha na sociedade como flexível e dependente da época e cultura consideradas. Os discursos-síntese a seguir ilustram duas destas categorias:

As crianças são muito inteligente, então elas qué fazê tudo, até o que não deve, elas querem fazê.
Quando a gente conversa ele (criança de 2 anos) entende o que eu tô falando! Eu fico meio assim, de não sabê explicá, às vezes, o que ela (criança de 5 anos) me pergunta né?

(discurso-síntese do grupo de mães usuárias de creche)

Desde pequenininha, desde que ela começô a falá, né, ela tava pedindo que queria ir prá escola. Sempre com um caderninho, um lapizinho na mão e os irmão mais velho sempre ensinando. Então, quando foi chegando os 4, 5 aninhos, a curiosidade era sabê quando ía chegá o dia dela í pro colégio.

(discurso-síntese do grupo de mães não usuárias de creche) 
Para estas mães, portanto, falar das características da criança de hoje, de sua natureza infantil, significa chamar de natural o meio social e cultural ao qual a criança está ligada (Muniz, 1999; Pereira \& Souza, 1998). Nos dois grupos, as mães fazem comparações de sua geração com a de seus filhos, concluindo que houve uma transformação nas famílias (primeiro meio da criança), passando de um modelo hierárquico para outro igualitário, no qual houve um declínio da autoridade parental ao longo dos anos (Caldana, 1995). Há também, por parte do grupo de não usuárias de creche, referência a um fenômeno recente, o compartilhamento da educação e cuidado da criança de zero a seis anos entre duas instituições sociais distintas - família e creche. No discurso-síntese apresentado este encaminhamento é uma solicitação da própria criança, denotando que as creches e pré-escolas constituem um espaço para descoberta do mundo para muitas crianças (Bujes, 2001).

A respeito das necessidades das crianças entre zero e 6 anos, encontram-se no Quadro 1 as categorias: Limite é importante; Ir conversando, explicando; Cuidar, dar carinho, atenção; Depende muito da gente; Deixar mais à vontade. Estas indicam que as mães pertencentes aos dois grupos parecem entender que cada época tem uma maneira própria de considerar o que é ser criança e de caracterizar as mudanças que ocorrem com ela ao longo da infância, bem como, os ajustes necessários nas práticas educativas (Bujes, 2001). Fica aqui evidenciado o reconhecimento por parte dos dois grupos de que a criança é diferente do adulto, tem períodos de maior dependência física e sócioemocional, estando, portanto, mais vulnerável e em processo de formação de hábitos, atitudes e valores; entretanto também se reconhece que, como os adultos, as crianças têm interesses, aptidões, vontades e posicionamentos próprios.

O Quadro 2, apresenta as categorias que dizem respeito ao conjunto temático "Dificuldades na criação dos filhos atualmente”. Estas categorias, bem como as falas que as originaram, evidenciam uma preocupação com aspectos sócio-culturais atuais e abrangentes.

Quadro 2: Categorias referentes a: "Dificuldades na criação dos filhos atualmente”.

\begin{tabular}{l|l}
\hline \multicolumn{1}{c|}{ Mães usuárias de creche } & \multicolumn{1}{c}{ Mães não usuárias de creche } \\
\hline $\begin{array}{l}\text { Influência da televisão } \\
\text { Violência }\end{array}$ & \\
Falta de estabilidade financeira, desemprego & Televisão \\
Não saber se está educando certo & Violência \\
Ficar pouco tempo com os filhos & Näo ter o direito de educar os filhos \\
Preconceito, discriminação & Papel do homem e da mulher mudou \\
Não ter com quem dividir a criação dos filhos & \\
\hline
\end{tabular}

Ao indicar a televisão como um fator relacionado às dificuldades em se criar filhos atualmente, fica evidenciado nas falas destas mães a influência deste tipo de mídia no consumo da população infantil. Deve-se acrescentar também a apropriação feita pela criança da linguagem veiculada por este meio, aspectos apontados por Merlo-Flores (1999) como um dos níveis de interferência dos programas televisivos no comportamento das crianças. As mães destacaram ainda que a televisão deturpa os valores da família. A comunidade científica caminha nesta direção ao ressaltar a internalização de valores agressivos pela criança através da programação televisiva que resultaria em comportamentos violentos
(Gomide, 2000; Strasburger, 1999). Os cientistas colocam ainda o problema da diminuição da comunicação nas famílias, pois estas gastam os momentos que permanecem juntas vendo televisão (Gomide, 2002; Gomide, Bussadori, Berri, Sabbag \& Furtado, 2003).

Eles vêem televisão, já pensam igual, e... Não é igual ao nosso tempo, que a gente se conformava com qualquer tipo de luva, qualquer tipo de calçado... Hoje eles querem roupa de marca,..., $O$ meu, de 5 anos, diz:- mãe com essa (roupa) não, não fica 'massa'! Já tá co'aquele linguajar da televisão. O que passa na televisão tá deturpando os valores da família. 
(discurso-síntese do grupo de mães não-usuárias de creche)

Ao falar sobre a violência urbana como uma das dificuldades atuais em se criar os filhos, as mães indicam a premência deste problema no viver urbano, acompanhado das questões a ele afeitas como a insegurança, a impunidade e o medo (Minayo, 1999; Rizzini, 1993; Rocha, 1992; Zaluar, 1996). É nítida a interferência destes fenômenos na qualidade de vida das famílias e, em destaque, na das crianças pequenas que, segundo suas mães, vivem "presas para dentro do portão, em suas próprias casas”. As famílias deixam de freqüentar os espaços públicos, antes destinados ao lazer infantil por estarem eles servindo a outros fins.

Antigamente você não tinha perigo de violência, as crianças eram mais soltas! Hoje em dia é, se ele tá em casa, estou com o portão tudo trancado, ele não fica nem lá na frente, mesmo se tiver trancado. .. Existe a violência desde dentro de casa quanto fora, o problema da bebida (do marido), um erro eu acho que é o pai chegar bêbado em casa, né?

(discurso-síntese do grupo de mães usuárias de creche)

Junto às mães usuárias de creche pôde-se constatar a preocupação com a segurança de seus filhos durante a permanência dos mesmos na instituição, uma vez que têm ocorrido assaltos e roubos nas mesmas, ainda que fora do horário de atendimento das crianças. Discorreram também sobre o vandalismo em áreas públicas de lazer infantil e da comunidade em geral, que foram totalmente descaracterizadas e destruídas; espaços antes destinados ao lazer são hoje ocupados por adultos e jovens para consumo de álcool e droga.

Essas impressões das mães parecem denotar conseqüências comuns de um aumento demográfico acelerado, da falta de trabalho e de condições precárias de vida, que compõem o círculo da violência (Zaluar, 1996). No entanto, para Milani (1999) esse afastamento das famílias dos espaços públicos, entendido como uma forma de não participação comunitária, acaba contribuindo para a manutenção da criminalidade e da violência.

A categoria Não ter com quem dividir a criação dos filhos alude à debatida concepção de maternidade, fruto de um longo processo histórico-cultural, como um mecanismo que, à revelia de ser mítico, impinge às mulheres, em muitos casos, a responsabilidade total pelos filhos e simultaneamente a subtrai do compromisso dos homens perante o filho, ou filha, por eles gerados. O espaço social feminino, ainda hoje, se mostra bastante atrelado à maternidade, enquanto que o masculino pode estar totalmente desvinculado da paternidade (Grisci, 1994; Trindade, 1998; Trindade \& cols., 1997). Isto, ao mesmo tempo que isenta os homens de compartilhar a experiência de criar e educar seus filhos, onera esta experiência para as mulheres, conforme pode-se verificar no discurso-síntese abaixo.

Não tenho com quem dividi a criação dos filhos, é muito duro! Depende tudo da mãe, da mãe... e nem sempre você tem aquele tempo prá ensiná, prá explicá, prá dá carinho. Você acaba com todas as dispesas... e a criança vai crescendo assim, com a falta do pai, como que diz, ela fica só.

(discurso-síntese do grupo de mães usuárias de creche)

No Quadro 3 indicam-se as categorias referentes ao conjunto temático "Erros comuns na educação dos filhos” e pode-se notar na fala das participantes a preocupação em agir de acordo com o que está, ou melhor, estaria pré-estabelecido, mas que no entanto, não se conhece ou não se tem certeza.

Quadro 3: Categorias resultantes de: "Erros comuns na educação dos filhos”.

\begin{tabular}{l|l}
\hline \multicolumn{1}{c|}{ Mães usuárias de creche } & \multicolumn{1}{c}{ Mães não usuárias de creche } \\
\hline Quando a gente bate & Meu marido faz uma coisa, eu faço outra \\
Eu grito muito & Xingar \\
Sai umas palavrinhas que não eram para sair & Deixar de dar atenção \\
Não admitir o que o teu filho faz & Fazer as vontades dele (do filho), mesmo que ele esteja errado \\
Mentir & Mentir \\
Não explicar o porque & Brigar com o marido na frente das crianças \\
Dar muüta liberdade & \\
Brigar com teu marido & \\
\hline
\end{tabular}


As concepções sobre as atitudes parentais que não estão de acordo com o que possa ser adequado na educação dos filhos ora se orientam externamente, com o que é ou pode ser socialmente desejado (Ballesteros, 1996), ora internamente, considerando os efeitos destas atitudes na relação intra-familiar e no desenvolvimento da criança. Na reprodução dos discursos-síntese abaixo, apontam-se estes dados:

Quando a gente bate, a gente se arrepende. Vê que batendo não resolve né, acho que conversando é que resolve né? O nervosismo que a gente passa no dia a dia, a gente não tem que descarregar, mas às vezes você tá tão saturado, que até esquece disso!

(discurso-síntese do grupo de mães usuárias de creche)

Meu marido faiz uma coisa e eu faço outra. Às vezes eu falo que não, ele vai dá e pronto. Compra salgadinho assim na hora do almoço daí ela (filha) perde a fome. Um põe de castigo o outro solta! Isso é ruim prá ele (filho)!

(discurso-síntese do grupo de mães não usuárias de creche)

Existe na literatura especializada uma discussão extensa a respeito do que possa ou não ser ade- quado em termos da educação de filhos; não se pretende desenvolvê-la aqui, tão pouco criar parâmetros novos para tal (Gomide, no prelo). Cabe, no entanto, enfatizar que as categorias deste conjunto temático refletem a mudança que se deu nas práticas educativas exercidas pelas famílias, passando do sentido moral para a preocupação central dos pais com o bem-estar emocional da criança, mesmo à revelia das necessidades dos demais integrantes da família; o modo de vida atual, nos espaços metropolitanos, acirra ainda mais esta condição, uma vez que é mais comum o isolamento das pessoas em seus núcleos familiares, implicando na falta de socialização da criança e conseqüente excesso de demanda das mesmas aos pais (Anolli \& Mantovani, 1998; Caldana, 1995).

O Quadro 4 reúne as categorias que fazem referência ao conjunto temático "Participação masculina na educação e no cuidado dos filhos”. Estas categorias indicam a coexistência de concepções afirmativas e concepções negativas sobre a emergência de uma nova figura de pai no contexto familiar e que, mesmo diante da grande diversidade de modelos familiares vigentes na sociedade contemporânea, mantém-se a concepção tradicional de maternidade e paternidade; por outro lado, afirma-se que há maior participação masculina no contexto familiar.

Quadro 4: Categorias resultantes de: "Participação masculina na educação e no cuidado dos filhos”.

\begin{tabular}{|c|c|}
\hline Mães usuárias de creche & Mães não usuárias de creche \\
\hline $\begin{array}{l}\text { Ele faz a parte dele } \\
\text { Brincar, é mais ele } \\
\text { Agora os pais participam mais } \\
\text { Gostaria que ele participasse mais } \\
\text { Brigo com ele }\end{array}$ & $\begin{array}{l}\text { O homem já não é discriminado } \\
\text { Hoje os pais participam mais } \\
\text { Quebra um galho } \\
\text { Näo é muito participativo }\end{array}$ \\
\hline
\end{tabular}

No dia-a-dia, as relações são desiguais, revelando uma "cristalização dicotômica" dos papéis masculino e feminino (Grisci, 1994; Trindade, 1998), apesar do reconhecimento de que na sociedade ocidental atual não existe nenhuma padronização rígida normatizando diferencialmente as condutas da mulher e do homem, inclusive no contexto familiar. (Trindade e cols., 1997). Note-se a contraposição entre os discursos-síntese a seguir:

A sociedade tá muito mais aberta pra questão do homem ajudar a mulher em casa, isso está, né?
Tá muito mais aberto, o homem já não é discriminado porque de repente, tá lavando uma louça ou lavando uma ropa. O homem tem condições, ele tem chances de se... digamos... de mostrar um pouco aquele lado afetivo, sem ser discriminado.

(discurso-síntese do grupo de mães não-usuárias de creche)

Eu queria que ele (o marido) tivesse um tempinho a mais pra conversá com eles (filhos) nas horas que precisasse entendeu? É dá atenção, o carinho, a educação, entende? Quando eu tô em casa 
eu acho de tudo pra fazê. E daí ele devia me ajudá, tipo dá pra fazê quase tudo que a gente faz, né? Sempre se tá os dois com o tempo disponível, a mãe é a responsável pelo filho. Eu gostaria que ele participasse mais, tipo trocasse, desse comida, porque só brincá tamém não tá adiantando.

(discurso-síntese do grupo de mães usuárias de creche)

Os depoimentos acima revelam um forte estereótipo sobre a "inabilidade masculina" para o trabalho doméstico e para o cuidado dos filhos. (Rezende \& Alonso, 1995). Estes discursos-síntese denotam um entendimento de que as ações dos homens no âmbito familiar requerem a supervisão e anuência da mulher; a autonomia para ele agir neste espaço não é delegada e, caso seja, dá-se com reservas. Em contrapartida e ao mesmo tempo, o pai é chamado a complementar a educação dada pela mãe, principalmente no momento de repreensão dos comportamentos não adequados dos filhos. Em função deste panorama, entende-se que um maior envolvimento dos pais na educação e cuidado dos filhos permanece comprometido, não sendo bom para nenhum dos envolvidos (pai, mãe e criança).

\section{Conclusão}

Este estudo descritivo veio contribuir para o conhecimento de alguns aspectos próprios da realidade das mães de camadas populares do município pesquisado e das concepções que elas têm e compartilham sobre a criança e suas necessidades.

As participantes, tanto do grupo de usuárias como do de não usuárias do sistema público de creches, percebem especificidades no processo de desenvolvimento dos filhos, indicando diferentes características e necessidades nestes seis primeiros anos de vida. Elas reconhecem as inúmeras modificações sociais e familiares dos últimos anos e as implicações desta situação na criação dos filhos. As mães dos dois grupos entendem os conceitos de paternidade e maternidade como relações que são construídas em seus espaços sociais, familiares e individuais e esta concepção indica que o homem "pode tudo que a mulher sempre pôde” em relação aos filhos e a casa; mas também evidencia a compreensão idiossincrática da situação, ao destacarem que "cada caso é um caso".

Os dados obtidos indicam que há similaridade nas concepções das mães que compõem ambos os grupos em relação aos assuntos que envolvem infância e práticas de cuidado e educação no contexto familiar. Isto sugere que a experiência em compartilhar os cuidados e educação dos seus filhos com um serviço institucional público não traz implicações sobre as concepções destas mães, no que diz respeito aos temas aqui discutidos.

\section{Referencias Bibliográficas}

Anolli, L. \& Mantovani, S. (1998). Além da Creche: o tempo para as famílias. Em: A. Bondioli;. S. Mantovani. Manual de Educação Infantil: de 0 a 3 anos - uma abordagem reflexiva (pp. 277301). Porto Alegre: Artmed.

Áries, P. (1981). História Social da Criança e da família. Rio de janeiro: ABDR- Editora Afiliada.

Ballesteros, R.F. (1996). Evaluación en Psicologia de la Salud: algunos problemas metodológicos. Em: M.M. Casullo. (Org.), Evaluación Psicológica en el Campo de la Salud (pp. 39-89). Barcelona: Paidós.

Bondioli, A. \& Mantovani, S. (1998). Manual de Educação Infantil: de 0 a 3 anos - uma abordagem reflexiva. Porto Alegre: Artmed.

Brasil. (2000). Ministério do Planejamento, Orçamento e Gestão. Fundação Instituto Brasileiro de Geografia e Estatística. Pesquisa sobre Indicadores Sociais e População. Rio de Janeiro, MPOG/IBGE/DP/DPIS.

Bufalo, J.M.P. (1997). Creche: lugar de criança, lugar de infância. Um estudo sobre as práticas educativas em um CEMEI de Campinas. Dissertação de Mestrado. Campinas: FE/ UNICAMP.

Bujes, M.I.E. (2001). Escola Infantil: pra que te quero? Em: C. Craidy \& G. E. Kaercher. (Orgs.), Educação Infantil: pra que te quero? (pp.1522). Porto Alegre: Artmed. 
Caldana, R.H.L. (1995). A Educação de Filhos em Camadas Médias: Transformações no Ideário e Orientação de Pais. Temas em Psicologia, 1,109121.

Carvalho, A.M.A. \& Beraldo, K.E. (1989). A Interação Criança-Criança Ressurgimento de uma Área de Pesquisa e suas Perspectivas. Cadernos de Pesquisa, 71, 55-61.

Faria, A.L.G. de. (1999). O espaço físico como um dos elementos fundamentais para uma pedagogia da educação infantil. Em: A.L.G. de Faria \& M.S. Palhares (Orgs.), Educação Infantil pósLDB: rumos e desafios (pp.67-98). Campinas: Autores Associados - FE/UNICAMP; Florianópolis: UFSC; São Carlos: UFSCar.

Ferreira, M.C. (1988). A Pesquisa na Universidade e a Educação da Criança Pequena. Cadernos de Pesquisa, 67, 79-89.

Gagnebin, J. (1997). Infância e Pensamento. Em: P. Ghiraldelli Júnior. (Org.), Infância, Escola e Modernidade. Cortez/Curitiba: UFPR.

Geis, R.M. (1994). Criar ou Educar Crianças? Estudo das Representações de Mães e Educadoras sobre o Papel da Creche. Tese de Doutoramento. São Paulo: IPUSP.

Gomide, P.I.C. (2000). Efeito de Filmes Violentos em Comportamento Agressivo de Crianças e Adolescentes. Psicologia: Reflexão e Crítica,13(1), 20-34.

Gomide, P.I.C. (2002). Crianças e Adolescentes em Frente à TV: o que e quanto assistem de televisão. Psicologia Argumento,19(30), 17-28.

Gomide, P.I.C. (no prelo). Pais Presentes, Pais Ausentes - Regras e Limites. Editora Vozes, Petrópolis.

Gomide, P.I.C., Bussadori, D.J., Berri, G C., Sabbag, G.M. \& Furtado, M.S. (2003). A influência da TV e dos estilos parentais nos horários de refeição das famílias. Psicologia Argumento, 21(32), 27-35.

Grisci, C.L.I. (1994). Ser mãe: produção dele, reprodução dela. Em: R. S. Cardoso (org.), É uma mulher... (pp. 29-51) Petrópolis: Vozes.
Kuhlmann Júnior, M. (1998). Infância e Educação Infantil: uma abordagem histórica. Porto Alegre: Mediação.

Lefèvre, F., Lefèvre, A.M.C. \& Teixeira, J.J.V. (2000). O Discurso do Sujeito Coletivo: uma abordagem metodológica em Pesquisa Qualitativa. Caxias do Sul: EDUCS.

Maistro, M.A. (1997). As Relações Creche-Famílias: um estudo de caso. Dissertação de Mestrado. Santa Catarina: UFSC.

Merlo-Flores, T. (1999). Por que Assistimos à Violência na Televisão? Pesquisa de campo argentina. Em: U. Carlsson \& C. von Feilitzen (Orgs.), A Criança e a Violência na Mídia (pp.57-78). São Paulo: Cortez.

Merisse, A. (1996). A Infância e seus Lugares: um estudo sobre as concepções de Mães e Funcionárias de Creche. Tese de Doutorado. São Paulo: IPUSP.

Milani, F.M. (1999). Adolescência e Violência: mais uma forma de exclusão. Educar (pp.101- 114). Curitiba: Editora da UFPR.

Minayo, M.C.S. (1992). O Desafio do Conhecimento: pesquisa qualitativa em saúde. São Paulo: Hucitec-Abrasco.

Minayo, M.C.S. (1999). Fala Galera: Juventude, Violência e Cidadania. Rio de Janeiro: Garamond.

Moro, C.S. (2002). Infância e Educação Infantil Pública: Concepções maternas. Dissertação de Mestrado, Curitiba: UFPR.

Muniz, L. (1999). Naturalmente Criança: a educação infantil de uma perspectiva sociocultural. Em: S. Kramer \& et al. (Orgs.), Infância e Educação Infantil (pp. 243-268). São Paulo: Papirus.

Oliveira, Z. de M.R. (1988). Jogos de Papéis: uma perspectiva para a análise do desenvolvimento humano. Tese de doutoramento, São Paulo: IPUSP.

Pedrosa, M.I. \& Carvalho, A.M. (1995). A Interação Social e a Construção da Brincadeira. Cadernos de Pesquisa, 93, 60-65. 
Pereira, R.M.R. \& Souza, S.J. e (1998). Infância, Conhecimento e Contemporaneidade. Em: S. Kramer \& M.I. Leite (Orgs.), Infância e Produção Cultural (pp.25-42). Campinas: Papirus.

Rezende, A.L.M. de \& Alonso, I.L K. (1995). O Perfil do Pai Cuidador. Revista Brasileira de Crescimento e Desenvolvimento Humano, 5(1/2), p.6681.

Rizzini, I. (1993). A Criança no Brasil Hoje: desafio para o terceiro milênio. Rio de Janeiro: Ed. da Universidade Santa Úrsula.

Rocha, S. (1992). Pobreza Metropolitana, Balanço de uma Década. Perspectivas da Economia Brasileira. Rio de Janeiro: IPEA.

Rosemberg, F. (1998). Educação Infantil nos Estados Unidos. Em: F. Rosemberg \& M.M. Campos. (Orgs.), Creches e Pré-escolas no Hemisfério Norte. (pp. 15-101). São Paulo: Cortez, Fundação Carlos Chagas.

Rossetti-Ferreira, M.C. \& Oliveira, Z. de M.R. de (1993). O Valor da Interação Criança-Criança em Creches no Desenvolvimento Infantil. $\mathrm{Ca}$ dernos de Pesquisa,87, 62-70.

Rosseti-Ferreira, M.C., Piotto, D.C., Chaguri, A.C., Mello, A.M., Silva, A.P.S. da, Eltink; C., Yazlle, C., Carniel, I.C., Sordi, G., Baldin, L.S.A., Frederick, M.I.B., Morais, R. \& Besani, V. (1998). Promoção da Qualidade e Avaliação na Educação Infantil: uma experiência. Cadernos de Pesquisa, 105, 52-77.

Silveira, V.P. da. (1997). O Mito da Infância na Educação Pré-escolar no Brasil. Saúde, Sexo e Educação. Rio de Janeiro, abr./jun., p. 18-23.

Souza, S.J. e (1994). Resignificando o desenvolvimento da criança a partir de uma teoria crítica da cultura. Encontro "Criança dos 0 a 6 anos. Que Perspectivas?”, UNICEF, Cabo Verde, (mímeo).

Strasburger, V. (1999). Os adolescentes e a mídia: Impacto psicológico. Artmed: Porto Alegre.

Trindade, Z.A. (1998). Concepções de Maternidade e Paternidade: o convívio atual com fantasmas do século XVIII. Em: L. de Souza, M.F.Q. de
Freitas \& M.M.P. Rodrigues. (Orgs.), Psicologia: reflexões (im)pertinentes (pp.129-155). São Paulo: Casa do Psicólogo.

Trindade, Z.A., Andrade, C.A. \& Souza, J.Q. de (1997). Papéis Parentais e Representações da Paternidade: a perspectiva do pai. Psico, 28(1), 207-222.

Ugazio, V.(1992). Manuale di Psicologia Educativa: Prima Infanzia. Firenze: La Nuova Itália.

Unicef. (2000). Situação da Infância Brasileira. Brasília: UNICEF.

Zaluar, A. (1996). Da Revolta ao Crime S. A.. São Paulo: Moderna. 